\title{
Continuous flow phantom for the calibration of an ultrasonic transit- time flowmeter
}

\author{
Fellipe Allevato Martins da Silva*, Marco Antônio von Krüger, Wagner Coelho de Albuquerque Pereira
}

\begin{abstract}
Introduction: Ultrasound Transit-Time flowmeters are based on the fact that the time required for an ultrasound pulse to propagate through a given distance in a moving medium is a function of the vectorial sum of pulse propagation velocity and medium velocity. The most common application of this flowmeter in medicine is in the evaluation of blood flow in arteries and veins during heart vascular surgery. The present article describes the design, construction and evaluation of a flow phantom for transit-time flowmeters calibration. Methods: Basically, it is a hydraulic circuit containing degassed and distilled water. In such a circuit, a constant differential water level is established between two columns that are interconnected by tubes with defined resistance, which determines a known flow rate. A basic theoretical model to estimate the system Reynolds Number and resistance was developed. Results: A flow range between $4.43 \pm 0.18 \mathrm{ml} . \mathrm{min}^{-1}$ and $106.88 \pm 0.27 \mathrm{ml} . \mathrm{min}^{-1}$ was found to be compatible with physiological values in small vessels. The pressure range was between $0.20 \pm 0.03$ $\mathrm{cmH}_{2} \mathrm{O}$ and $12.53 \pm 0.07 \mathrm{cmH}_{2} \mathrm{O}$, and the larger Reynolds Number was 1134.07. Experimental and theoretical resistance values were similar. Conclusion: A reproducible phantom was designed and built to be assembled with standard low-cost materials and is capable of generating adjustable and continuous flows that can be used to calibrate TTFM systems.
\end{abstract}

Keywords Flow phantom, Calibration, Flowmeter, Ultrasound, Transit-time.

\section{Introduction}

Cardiovascular and cerebrovascular diseases are among the most important causes of death according to the World Health Organization. This is mainly due to atherosclerosis, a heterotopic fat deposit in the large arteries' intima, which may cause atherosclerotic plaques (Berry et al., 2007; Mello-Aires, 2008). Such changes in the vessel structure may lead to embolism, calcification and/or clogging, which are often corrected through surgical revascularization intervention. In these surgeries, the flow measurement (arterial, venous or graft) is very useful as it allows better procedure quality control to prevent operating errors that may lead to low flow and consequent vasospasm (Walpoth et al., 1998).

Angiography is the gold-standard assessment for blood vessels and graft patency during surgical procedures and clinical examination (Berry et al., 2007). However, there are modern techniques for measuring blood flow that do not require direct access to the vessel lumen. The main commercial systems available for this purpose are ultrasonic and electromagnetic devices. The electromagnetic flowmeter is efficient in detecting graft stenosis; however, it is sensitive to the patient hematocrit rate, especially in smaller vessels, such as the internal thoracic artery (Canver et al., 1997; Hirotani et al., 2001; Tabrizchi and Pugsley, 2000).
Ultrasonic flowmeters are based on Doppler or Transit-time phenomena. The Doppler flowmeter indicates only flow velocity and depends on other variables in addition to the particle speed, for example, distribution of blood cells within the vessel and transducer beam angle (Beldi et al., 2000; Walpoth et al., 1998).

The Transit-time Flow Meter (TTFM) depends only on the fluid velocity, independent of the flow pattern, red blood cell concentration and insonation angle, and presents good repeatability and reproducibility (Laustsen et al., 1996; Sanderson and Yeung, 2002). The working principle of TTFM is that the time required for an ultrasound pulse to propagate through a given distance in a moving medium is a function of the vectorial sum of the pulse propagation velocity and the medium velocity (Drost, 1978).

Flow phantoms are hydraulic circuits capable of generating known and adjustable flow patterns, providing the necessary conditions for flowmeter calibration. For the ultrasonic Doppler flowmeter method evaluation, introducing scattering particles suspended in the blood-mimicking fluid must be considered (Poepping et al., 2004; Rickey et al., 1995). However, backscatter is not needed for the TTFM method; instead, only the time difference of a pulse propagating in opposite directions. 
The physiological laminar flow is the most common and has parameter that are easier to quantify. Turbulent flow is more difficult to characterize and introduces measurement errors, presenting sudden changes in direction and increasing the speed of flow near the vessel wall where the TTFM sensitivity is lower (Dean et al., 1996), as Gordon (1995) confirmed experimentally for the case of turbulence caused by stenosis.

Among the TTFM calibration phantoms found in the literature, some use hydrostatic pressurization (Gordon, 1995; Transonic..., 2009) while others employ peristaltic pumps (Beldi et al., 2000; Groom et al., 2001). The materials employed in the measurement region ranged from synthetic materials, such as latex (Drost, 1978; Transonic..., 2009) and dialysis tubing (Bednarik and May, 1995; Gordon, 1995), to biological materials, such as saphenous human vein grafts (Beldi et al., 2000; Groom et al., 2001), carotid arteries of rats (Amaral and Michelini, 1997), sheep (Lundell et al., 1993) and pigs (Beldi et al., 2000). Water is the working fluid that is normally employed, but there are also reports of the use of saline solution in experiments with biological materials (Beldi et al., 2000; Groom et al., 2001). Furthermore, there is a case where red blood cells were dissolved in bypass fluid (Normosol -R) (Groom et al., 2001).

There is no specific pattern used to calibrate the TTFM method. Known methods do not have a common experimental protocol and incur a high implementation cost (Amaral and Michelini, 1997; Bednarik and May, 1995; Beldi et al., 2000; Gordon, 1995; Groom et al.,
2001; Lundell et al., 1993; Transonic..., 2009), which indicates the importance of establishing a well-defined method for TTFM calibration that is inexpensive and has an easy acquisition phantom.

This work reports on the design, construction and calibration of the continuous flow phantom capable of generating comparable values for the flow range observed in coronary grafts (approximately between 0 and $100 \mathrm{ml} / \mathrm{min}$ ) to calibrate a TTFM.

\section{Methods}

\section{Phantom constituent materials}

The designed phantom (Figure 1) consists of two parts: $(i)$ a pressurization system $(a-d, e-f)$ filled with $1000 \mathrm{~mL}$ of degassed distilled water, and (ii) a measurement region $(d-e)$. The components of the phantom are as follows:

(1) Peristaltic pump (102FD / R - Watson Marlow Bredel - USA);

(2) Two cylindrical reservoirs (C1 and C2), which are plastic beakers which have a $1000 \mathrm{~mL}$ capacity each, $64.5 \mathrm{~mm}$ inner diameter and $420 \mathrm{~mm}$ height and are equipped with connections located at their bases;

(3) Silicone interconnecting tubes $(c-d, e-f)$ with $6 \mathrm{~mm}$ internal diameter and $60 \mathrm{~cm}$ total lengths;

(4) Three exchangeable silicone tubes used in the peristaltic pump $(a-b)$ with three internal diameters - $1.6 \mathrm{~mm}, 3.2 \mathrm{~mm}$ and $4.8 \mathrm{~mm}$ - to provide three flow values. All tubes are 55

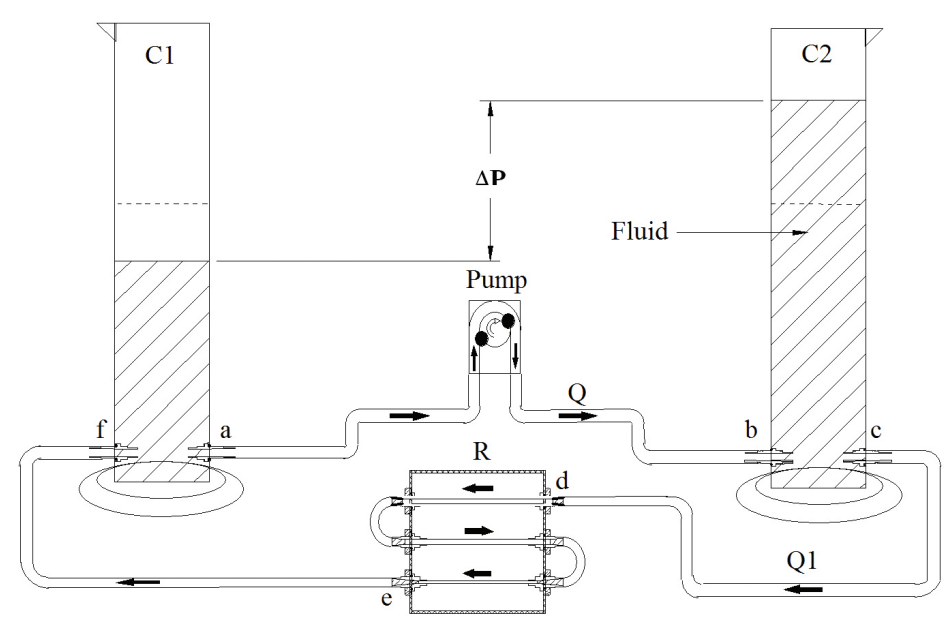

Figure 1. Hydraulic circuit schematic representation for the flow phantom in continuous mode. Arrows indicate the fluid direction. The pump has an average $Q$ flow rate and, when turned on, transfers fluid from $C 1$ column to $C 2$ column, generating the flow gradient in $c$ - $d$ - $e-f$. A dynamic equilibrium is reached when the $Q$ flow rate in $a-b$ is equal to $Q 1$ (in $c-d-e-f$ ). The $R$ resistance represents the total fluid movement resistance in $c$ - $d-e-f . \Delta P$ is the fluid level difference between $C 1$ and $C 2$ during dynamic equilibrium, corresponding to a pressure difference between $c$ and $f$. 
$\mathrm{cm}$ long with a $1.6 \mathrm{~mm}$ wall thickness. One of these three tubes makes the $C 1$ and $C 2$ columns interconnection via peristaltic pump.

(5) Measurement region $(d-e)$ described in detail below.

\section{Measurement region}

In Figure 1, the measurement region $(d-e)$ is where the flowmeter transducer that is to be calibrated is placed. It consists of a plastic frame $(15.5 \mathrm{~cm} \times 18.5 \mathrm{~cm})$ with three tubes representing the vessels that are $140 \mathrm{~mm}$ in length with inner diameters of $4.5 \mathrm{~mm}, 3 \mathrm{~mm}$ and $2 \mathrm{~mm}$. The tubes are serially connected, with the flow starting in the larger caliber tube and ending in the smaller diameter one, resulting in three different flow velocities for the same flow rate. These tubes are thin walled $(0.2 \mathrm{~mm})$ to minimize the ultrasonic beam interference. The connectors are manufactured with tapered internal bores (an angle of approximately $6^{\circ}$ ) to ensure a smooth transition between the connecting pipes and vessels to minimize turbulence. The $c-d$ interconnecting tube is coupled to the $4.5 \mathrm{~mm}$ tube, while the other $e-f$ interconnecting tube is coupled to the $2 \mathrm{~mm}$ tube from the opposite side of the $d$-e frame. The interconnections between the remaining connectors on the right and left sides of the frame were accomplished using U-shaped silicone tubes with a $6 \mathrm{~mm}$ internal diameter and $10 \mathrm{~cm}$ length.

\section{Flow phantom operation}

When the pump is off, there is no difference in level between the fluids in the $C 1$ and $C 2$ columns because of the $c-d-e-f$ connection, meaning that the pressure difference between the $c$ and $f$ points (the base of each column) is zero and that the system is in static equilibrium.

When the pump is turned on, a $Q$ flow is generated towards $a \rightarrow b$, creating a difference in the level between the fluids in the $C 1$ and $C 2$ columns that is equivalent to the pressure difference $(\Delta P)$ between $c$ and $f$, as seen in Figure 1. This level difference increases and indicates that dynamic equilibrium occurs when the $Q 1$ flow created in the $c \rightarrow d \rightarrow e \rightarrow f$ direction equals the flow generated by the pump (i.e., $Q 1=Q$ ). Each $Q$ value is a function of the pump voltage and corresponds to an identical $Q 1$ flow, as determined by $\Delta P$ and the total $c-d-e-f$ resistance of the circuit, which is also a function of $Q 1$.

The maximum backpressure resistance (reflux) of the peristaltic pump is $612 \mathrm{cmH}_{2} \mathrm{O}$, which is much higher than the maximum pressure in this system $\left(12.53 \mathrm{cmH}_{2} \mathrm{O}\right)$ and thus prevents mechanical losses. The pump flow is pulsatile, and each half cycle always has the same pumped volume. Thus, the $Q$ average flow rate (total volume by time) in $a-b$ is a direct function of the ejected volume for each cycle and the pump rotation rate. The speed of rotation can be varied as a function of the voltage (in this case, between 4 and 12 volts). It is activated by a continuous electric motor (6215A Power Supply - HP - USA) in parallel with a $10 \mu \mathrm{F}$ capacitor (Sangamd Type 500 - USA), which filters the voltage oscillations of the electric motor. The pump calibration was performed at the beginning of the experiment, as explained below.

\section{Flow and pressure measurement}

The peristaltic pump calibration employed can be described as follows: two containers $(500 \mathrm{~mL}$ capacity Becker), distilled water, a precision balance, a voltmeter and a timer. Assuming that the resistance in the $a-b$ segment is insignificant, it can be said that $Q$ is a function of the voltage supplied to the motor (which determines its rotational speed) and the internal diameter of the pumping tube.

The voltmeter (Tek DMM254 - Tektronix - USA, with a resolution of 0.01 volts) was used to measure and regulate the voltage supplied to the pump for the transfer of water flow from the first to the second container during one minute (controlled with a digital timer of 0.1 second resolution). The amount transferred was measured by weighing the mass of the pumped water with a precision balance (E200 - Mettler - Switzerland, with 0.01 grams resolution). The three available pumping tubes (1.6 mm, $3.2 \mathrm{~mm}$ and $4.8 \mathrm{~mm}$ internal diameters) were used, and for each tube, the voltage was varied from 4 to 12 volts in steps of 1 volt. Each combination (tubes $\times$ voltages) was repeated six times to minimize potential start and end timing errors.

Therefore, using the pump calibration results (tubes $\times$ voltages), we can define the $Q$ average flow rate in the $a-b$ segment corresponding to the ejected volume in one minute. The measurement unit was $\mathrm{ml} \cdot \mathrm{min}^{-1}$, which is usually employed in human circulation flowmetry.

The measurement of the $\Delta P$ pressure difference in the system was obtained by measuring the level difference between the fluids in the $\mathrm{Cl}$ and $\mathrm{C} 2$ columns during phantom dynamic equilibrium (Figure 1). A millimeter scale with $0.1 \mathrm{~cm}$ resolution was attached to the columns to perform the measurement in terms of centimeters of water. In this measurement, the three types of pumping tubes $(1.6 \mathrm{~mm}, 3.2 \mathrm{~mm}$ and $4.8 \mathrm{~mm}$ internal diameters) were also employed to evaluate all of the $\Delta P$ possibilities for each of the nine voltage values (4 to 12 volts), and each combination was repeated six times. 


\section{Theoretical modeling}

The Re Reynolds number (Equation 1) is dimensionless and indicates whether the flow regime in a pipe is laminar or turbulent, with the fluid's main rheological characteristics considered in the flow phantom design.

$$
\operatorname{Re}=\frac{4 \rho Q}{\mu \pi D}
$$

where $\rho$ is density, $Q$ is the flow rate, $\mu$ is the fluid dynamic viscosity and $D$ is the tube internal diameter (Fox and McDonald, 2010).

According to Fox and McDonald (2010), in laminar flow (Re $\leq 2000)$, the fluid flows in laminae or parallel layers. In turbulent flow ( $R e \geq 3000)$, the particles are mixed in a nonlinear manner. In other cases, $(2000 \leq R e \leq 3000)$ one of two types of flow can occur.

Employing hydrostatic pressurization can ensure laminar flow as long as the condition described in Equation 2 is followed (Hein and O'Brien, 1992)

$$
L_{\min } \geq \frac{0,073 \rho Q}{\mu}
$$

where $L_{\min }$ is the minimum length of pipe in the measurement region.

The relationship between pressure, flow and resistance in this proposed hydraulic circuit phantom can be described by Equation 3 (Fox and McDonald, 2010):

$$
\Delta P=Q^{2} \cdot\left(R_{c}+R_{a}\right)
$$

where the difference in pressure $(\Delta P)$ between the two system reservoirs is equal to the flow rate squared $(Q)$ multiplied by the circuit intrinsic resistance $(R)$, which can be defined as the resulting resistance from the continuous straight pipe $\left(R_{\mathrm{c}}\right)$ and the accessories $\left(R_{\mathrm{a}}\right)$ that connect them.

In the laminar flow case, $R_{\mathrm{c}}$ can be calculated from Poiseuille Equation 4, which expresses the pressure fall in a horizontal tube of $L$ length (Fox and McDonald, 2010):

$$
\Delta P=\frac{128 \mu L Q}{\pi D^{4}}
$$

Equation 4 can be rewritten as:

$$
\Delta P=Q^{2}\left(\frac{128 \mu L}{\pi D^{4} Q}\right)
$$

From Equation 3, assuming no accessories in the tube $\left(R_{\mathrm{a}}=0\right)$ and applying $(5-3)$, Equation 6 is obtained:

$$
R_{c}=\frac{128 \mu L}{\pi D^{4} Q}
$$

$R_{\mathrm{a}}$ represents a specific resistance accessory or sudden change in internal diameter in a closed hydraulic system. $R_{\mathrm{a}}$ can be obtained from algebraic manipulations, resulting Equation 7 (Fox and McDonald, 2010):

$$
R_{a}=\frac{K 8 \rho}{\pi^{2} D^{4}}
$$

where $K$ is the dimensionless loss coefficient, which can be determined experimentally for each situation or using representative data found in the literature. Table 1 presents the most common cases of accessories in flow phantoms (Fox and McDonald, 2010).

\section{Results}

In Table 2, the values of $Q$ and $\Delta P$ obtained in each voltage $\mathrm{X}$ pumping tube diameter combination are presented with their respective uncertainties. The values of experimental and theoretical resistance are also shown.

The measurement of $Q$ and $\Delta P$ in the $c-d-e-f$ region covers the entire range of possible variation by combining all voltages ranging from 4 to 12 volts in increments of 1 volt, with each of the three pumping tubes $(1.6 \mathrm{~mm}, 3.2 \mathrm{~mm}$ and $4.8 \mathrm{~mm}$ internal diameters, respectively). Six measurements were performed for each combination to determine the flow rate and pressure difference. Flow rates ranged from $4.43 \pm 0.18$ ml. $\mathrm{min}^{-1}$ and $106.88 \pm 0.27 \mathrm{ml} \cdot \mathrm{min}^{-1}$ with expanded uncertainties obtained by multiplying the combined uncertainty of the measurement components (volume and time) by the coverage factor. The pressures ranged from $0.20 \pm 0.03 \mathrm{cmH}_{2} \mathrm{O}$ to $12.53 \pm 0.07 \mathrm{cmH}_{2} \mathrm{O}$,

\begin{tabular}{|c|c|c|c|}
\hline Input Type & & \multicolumn{2}{|c|}{$K$} \\
\hline Sharp edge input & - & \multicolumn{2}{|c|}{0.5} \\
\hline Gradual contraction & | & $\begin{array}{c}\mathrm{A}_{2} / \mathrm{A}_{1} \\
0.5 \\
0.25 \\
0.1\end{array}$ & $\begin{array}{r}\theta=10^{\circ} \\
0.05 \\
0.05 \\
0.05\end{array}$ \\
\hline Gradual expansion & i & $\begin{array}{c}\mathrm{A}_{2} / \mathrm{A}_{1} \\
1.3 \\
2.0 \\
3.0\end{array}$ & $\begin{array}{c}=6^{\circ} \\
0.35 \\
0.6 \\
0.7\end{array}$ \\
\hline Sharp edge output & प्य & & \\
\hline
\end{tabular}
and the combined uncertainties were obtained using the measurement uncertainty component (pressure).

The higher Re Reynolds number calculated from Equation 1 was 1134.07 . Because Re is directly

Table 1. Coefficients of losses $(K)$ for each accessory (Fox and McDonald, 2010). 
proportional to the $Q$ flow rate and inversely proportional to the $D$ pipe diameter, the higher $Q=106.88 \mathrm{ml} \cdot \mathrm{min}^{-1}$ and smaller $D=2 \mathrm{~mm}$ were employed. The value used for the water density $(\rho)$ was $1000 \mathrm{~kg} \cdot \mathrm{m}^{-3}$, and that for dynamic viscosity $(\mu)$ was $10^{-3} \mathrm{~kg} .(\mathrm{m} . \mathrm{s})^{-1}$.

The largest $L_{\min }$ predicted value for the measurement region $(d-e)$ is $13 \mathrm{~cm}$, which corresponds to the phantom system running at its highest $Q$ flow (which is $14 \mathrm{~cm}$ for this phantom). The minimum $L_{\min }$ distance required for a continuous flow to become laminar was calculated using Equation (2) (Hein and O'Brien, 1992).

The $R$ experimental value is calculated by Equation 3, which consists of the ratio between the $\triangle P$ and $Q$ experimental flow squared. The expanded uncertainties were determined by multiplying the combined uncertainty of the measurement components (volume, pressure and time) by the coverage factor. Theoretical $R\left(\mathrm{cmH} 2 \mathrm{O} \cdot \mathrm{min}^{2} \cdot \mathrm{ml}^{-2}\right)$ is calculated from the addition of $R_{\mathrm{c}}(c-d, e-f$, and the thin-walled tubes of the measurement region) and $R_{\mathrm{a}}$ (accessory connections, consisting of eight pieces), defined by Equations 6 and 7. In Figure 2, the curves of $R$ obtained in both forms are compared. The experimental and theoretical curves are similar, and the $R$ values are similar when there is higher flow (pumping tubes of 4.8 and $3.2 \mathrm{~mm}$ in diameter). However, the lowest flow rates $(1.6 \mathrm{~mm})$ are distant from each other.

In the scatter plot for the experimental and theoretical $R$ values for each of the pumping tubes $(4.8 \mathrm{~mm}, 3.2 \mathrm{~mm}$, and $1.6 \mathrm{~mm})$ in Figure 3, the $r$ Pearson correlation coefficients $(0.998,0.997$, and 0.957 , respectively) and the linear regressions with respective angular coefficient of $1.098,1.527$, and 1.950 are presented.

\section{Discussion}

This article aims to study and develop a phantom capable of generating continuous flow comparable

Table 2. Experimental values of average flow rate $\left(\mathrm{ml} \mathrm{min}^{-1}\right)$ and average system pressure $\left(\mathrm{cmH}_{2} \mathrm{O}\right)$, with respective expanded and combined uncertainty. Experimental resistance values $\left(\mathrm{cmH}_{2} \mathrm{O} \cdot \mathrm{min}^{2} \cdot \mathrm{ml}^{-2}\right)$, with expanded uncertainty and theoretical resistance values $\left(\mathrm{cmH}_{2} \mathrm{O} \cdot \mathrm{min}^{2} \cdot \mathrm{ml}^{-2}\right)$.

\begin{tabular}{|c|c|c|c|c|c|c|c|c|}
\hline $\begin{array}{c}\text { Pumping } \\
\text { tube } \\
(\mathrm{mm})\end{array}$ & volts & $\begin{array}{l}\text { Average } \\
\text { flow rate } \\
\left(\mathrm{ml} . \mathrm{min}^{-1}\right)\end{array}$ & $\begin{array}{c}\text { Average } \\
\text { flow rate } \\
\text { expanded } \\
\text { uncertainty }\end{array}$ & $\begin{array}{l}\text { Average } \\
\text { system } \\
\text { pressure } \\
\left(\mathrm{cmH}_{2} \mathrm{O}\right)\end{array}$ & $\begin{array}{l}\text { Average } \\
\text { system } \\
\text { pressure } \\
\text { combined } \\
\text { uncertainty }\end{array}$ & $\begin{array}{c}\text { Experimental } \\
\text { resistance } \\
\left(\mathrm{cmH}_{2} \mathrm{O} . \mathrm{min}^{2} .\right. \\
\left.\text { ml- }^{-2}\right)\end{array}$ & $\begin{array}{c}\text { Experimental } \\
\text { resistance } \\
\text { expanded } \\
\text { uncertainty }\end{array}$ & $\begin{array}{c}\text { Theoretical } \\
\text { resistance } \\
\left(\mathrm{cmH}_{2} \mathrm{O} .\right. \\
\left.\mathrm{min}^{2} \cdot \mathrm{ml}^{-2}\right)\end{array}$ \\
\hline 4.80 & 12.00 & 106.88 & 0.27 & 12.53 & 0.07 & $1.10 \mathrm{E}-03$ & $1.84 \mathrm{E}-05$ & $9.02 \mathrm{E}-04$ \\
\hline 4.80 & 11.00 & 97.58 & 0.43 & 11.03 & 0.09 & $1.16 \mathrm{E}-03$ & $2.64 \mathrm{E}-05$ & $9.75 \mathrm{E}-04$ \\
\hline 4.80 & 10.00 & 88.48 & 0.25 & 9.77 & 0.07 & $1.25 \mathrm{E}-03$ & $2.49 \mathrm{E}-05$ & $1.06 \mathrm{E}-03$ \\
\hline 4.80 & 9.00 & 79.15 & 0.59 & 8.17 & 0.09 & $1.30 \mathrm{E}-03$ & 4.12E-05 & $1.17 \mathrm{E}-03$ \\
\hline 4.80 & 8.00 & 69.90 & 0.28 & 7.17 & 0.09 & $1.47 \mathrm{E}-03$ & $5.09 \mathrm{E}-05$ & $1.31 \mathrm{E}-03$ \\
\hline 4.80 & 7.00 & 60.78 & 0.24 & 6.20 & 0.09 & $1.68 \mathrm{E}-03$ & 7.67E-05 & $1.49 \mathrm{E}-03$ \\
\hline 4.80 & 6.00 & 51.52 & 0.21 & 4.97 & 0.09 & $1.87 \mathrm{E}-03$ & $9.66 \mathrm{E}-05$ & $1.73 \mathrm{E}-03$ \\
\hline 4.80 & 5.00 & 42.28 & 0.25 & 3.97 & 0.04 & $2.22 \mathrm{E}-03$ & $6.35 \mathrm{E}-05$ & $2.08 \mathrm{E}-03$ \\
\hline 4.80 & 4.00 & 32.80 & 0.37 & 2.83 & 0.07 & $2.63 \mathrm{E}-03$ & $1.81 \mathrm{E}-04$ & 2.64E-03 \\
\hline 3.20 & 12.00 & 50.48 & 0.15 & 4.40 & 0.03 & $1.73 \mathrm{E}-03$ & 2.67E-05 & $1.76 \mathrm{E}-03$ \\
\hline 3.20 & 11.00 & 46.17 & 0.22 & 3.87 & 0.05 & $1.81 \mathrm{E}-03$ & $6.32 \mathrm{E}-05$ & $1.92 \mathrm{E}-03$ \\
\hline 3.20 & 10.00 & 41.88 & 0.13 & 3.37 & 0.04 & $1.92 \mathrm{E}-03$ & $6.30 \mathrm{E}-05$ & $2.10 \mathrm{E}-03$ \\
\hline 3.20 & 9.00 & 37.48 & 0.17 & 2.97 & 0.04 & $2.11 \mathrm{E}-03$ & 7.92E-05 & $2.33 \mathrm{E}-03$ \\
\hline 3.20 & 8.00 & 33.07 & 0.11 & 2.40 & 0.03 & $2.19 \mathrm{E}-03$ & $6.02 \mathrm{E}-05$ & $2.62 \mathrm{E}-03$ \\
\hline 3.20 & 7.00 & 28.72 & 0.20 & 2.07 & 0.05 & $2.51 \mathrm{E}-03$ & $1.63 \mathrm{E}-04$ & $3.00 \mathrm{E}-03$ \\
\hline 3.20 & 6.00 & 24.33 & 0.07 & 1.73 & 0.05 & $2.93 \mathrm{E}-03$ & $2.28 \mathrm{E}-04$ & $3.52 \mathrm{E}-03$ \\
\hline 3.20 & 5.00 & 20.02 & 0.14 & 1.28 & 0.05 & $3.19 \mathrm{E}-03$ & $3.52 \mathrm{E}-04$ & $4.25 \mathrm{E}-03$ \\
\hline 3.20 & 4.00 & 15.50 & 0.12 & 1.00 & 0.03 & $4.16 \mathrm{E}-03$ & 2.73E-04 & $5.45 \mathrm{E}-03$ \\
\hline 1.60 & 12.00 & 14.27 & 0.11 & 0.97 & 0.04 & $4.75 \mathrm{E}-03$ & $5.42 \mathrm{E}-04$ & $5.91 \mathrm{E}-03$ \\
\hline 1.60 & 11.00 & 13.12 & 0.15 & 0.87 & 0.05 & $5.04 \mathrm{E}-03$ & $7.76 \mathrm{E}-04$ & $6.41 \mathrm{E}-03$ \\
\hline 1.60 & 10.00 & 11.95 & 0.24 & 0.73 & 0.05 & $5.14 \mathrm{E}-03$ & $9.43 \mathrm{E}-04$ & 7.03E-03 \\
\hline 1.60 & 9.00 & 10.62 & 0.13 & 0.70 & 0.05 & $6.21 \mathrm{E}-03$ & $1.25 \mathrm{E}-03$ & $7.89 \mathrm{E}-03$ \\
\hline 1.60 & 8.00 & 9.48 & 0.22 & 0.60 & 0.03 & $6.67 \mathrm{E}-03$ & $7.55 \mathrm{E}-04$ & $8.82 \mathrm{E}-03$ \\
\hline 1.60 & 7.00 & 8.27 & 0.16 & 0.53 & 0.05 & $7.80 \mathrm{E}-03$ & $1.95 \mathrm{E}-03$ & $1.01 \mathrm{E}-02$ \\
\hline 1.60 & 6.00 & 7.00 & 0.18 & 0.40 & 0.03 & $8.16 \mathrm{E}-03$ & $1.36 \mathrm{E}-03$ & $1.19 \mathrm{E}-02$ \\
\hline 1.60 & 5.00 & 5.75 & 0.18 & 0.33 & 0.05 & $1.01 \mathrm{E}-02$ & $4.04 \mathrm{E}-03$ & $1.45 \mathrm{E}-02$ \\
\hline 1.60 & 4.00 & 4.43 & 0.18 & 0.20 & 0.03 & $1.02 \mathrm{E}-02$ & $3.34 \mathrm{E}-03$ & $1.87 \mathrm{E}-02$ \\
\hline
\end{tabular}




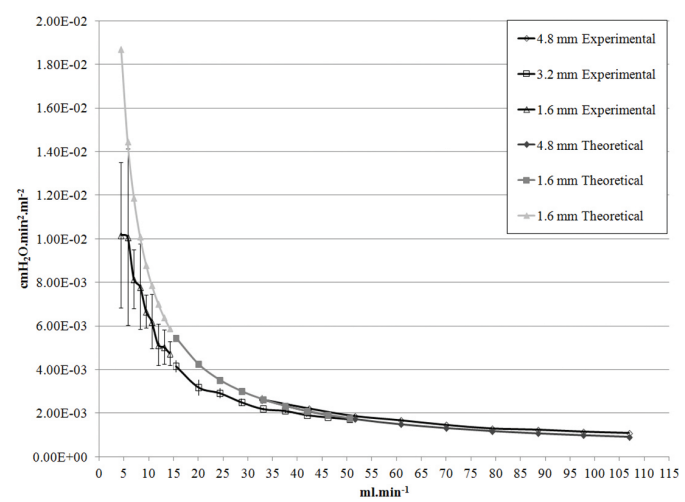

Figure 2. Experimental resistance $\left(\mathrm{cmH}_{2} \mathrm{O} \cdot \mathrm{min}^{2} \cdot \mathrm{ml}^{-2}\right)$ with expanded uncertainty and theoretical resistance $\left(\mathrm{cmH}_{2} \mathrm{O} \cdot \mathrm{min}^{2} \cdot \mathrm{ml}^{-2}\right)$ determined using the flow phantom with each of the three pumping tubes. The horizontal scale corresponds to the flow rates used in the experiment $\left(\mathrm{ml} \cdot \mathrm{min}^{-1}\right)$.

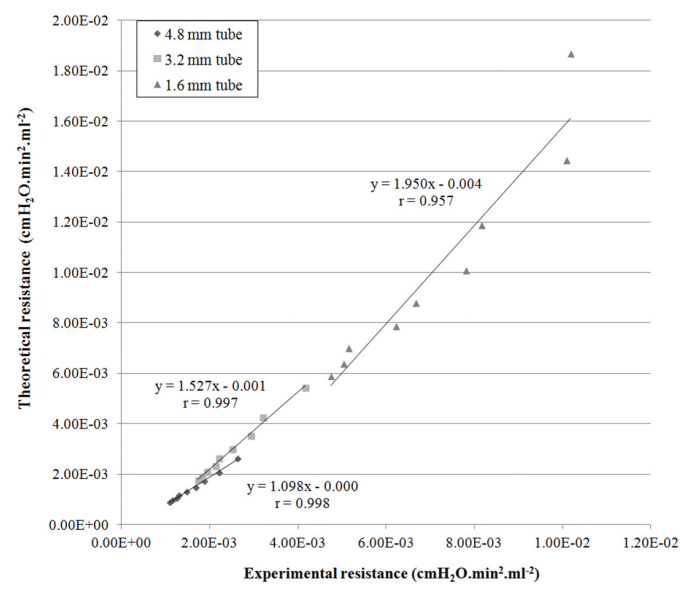

Figure 3. Scatter plots for $R$ experimental and theoretical resistance values in $\mathrm{cmH}_{2} \mathrm{O} \cdot \mathrm{min}^{2} . \mathrm{ml}^{-2}$ for each of the pumping tubes $(4.8 \mathrm{~mm}$, $3.2 \mathrm{~mm}$ and $1.6 \mathrm{~mm}$ ) with respective Pearson's correlation coefficients (r) $(0.998,0.997$, and 0.957$)$ and linear regressions.

with that found in coronary grafts. The primary motivation was to use this equipment in the calibration of an ultrasonic flowmeter based on the transit-time principle.

Flow phantoms for the calibration of ultrasonic flowmeters using the Doppler method can evaluate the performance of TTFM. However, the Doppler method requires fluids that generate scattering of the ultrasonic incident wave similar to that produced by the blood suspension organelles (Poepping et al., 2004; Rickey et al., 1995). This is not required for the flowmeters based on transit-time because they are only depend on the difference between the times of flight of a pulse propagating towards and backwards along the same path in which there is a moving fluid.

The TTFM measurement method does not require that the acoustic properties of the tube walls be similar to those of the vessel because the influence of these properties is naturally canceled by the transit-time subtraction procedure. Nonetheless, thin-wall silicone tubing was employed in this study to minimize the attenuation of the signal received by the device being tested. Poepping et al. (2004) opted to use silicone tubes in ultrasonic Doppler flowmeter for phantoms due to its stability and low attenuation. The flow is constant in the phantom described in this article; therefore, despite an initial transient, the viscoelastic behavior of the tubes used is not important.

The continuous flow system was chosen because it facilitates obtaining a laminar flow (more common in small arteries); additionally, turbulent flow may cause error in the TTFM measurement (Dean et al., 1996; Gordon, 1995). In the phantom presented in this article, the laminar flow in the measurement region for TTFM calibration is generated by hydrostatic pressurization (difference in level between the fluids columns). Both columns dampen oscillations originating from the peristaltic pump flow. Due to the large difference in diameter between the columns' and the tubes' pumping diameters, the variation of the water level in the columns during the pump cycle is negligible. Although it has been used for a continuous flow regime, by eliminating one of the circuit columns, the described phantom is able to generate pulsatile flow.

The flow phantoms used for calibrating TTFM that are described in the literature employ different materials and methods with some similarity to the phantom proposed here. No papers regarding a TTFM flow phantom designed with silicone tubes in the measurement regions were found. Water has been the most cited fluid (Bednarik and May, 1995; Drost, 1978; Gordon, 1995), except for cases in which salt solutions were employed in ex vivo veins and arteries (Amaral and Michelini, 1997; Beldi et al., 2000; Groom et al., 2001; Lundell et al., 1993). The use of hydrostatic pressure for pressurization was found in the Transonic System calibration manual (Transonic..., 2009). Gordon (1995) used a pressurized chamber created by a mechanical ventilator to generate a differential pressure.

Based on our results, it appears that the system produces flow rates $Q$ comparable with those of the human vascular system coronary arteries (MelloAires, 2008) and thus may be used to calibrate the TTFM. The $d$-e measurement region consists of the frame containing the three thin-walled tubes $(2,3-$, and $4.5 \mathrm{~mm}$ diameters) in series (Figure 1), and this arrangement provides three values of speed depending on the diameter of the tube in which the transducer is to be attached. 
The use of a millimeter scale affixed to the water columns led to satisfactory results when measuring $\triangle P$ at high gaps (obtained using the pumping tubes of $4.8 \mathrm{~mm}$ and $3.2 \mathrm{~mm}$ internal diameters). However, it was difficult to measure the $\Delta P$ in cases where the magnitude of the gap decreased and approached the read error. This measurement bias led to the low correlation coefficient between the experimental and theoretical $\mathrm{R}$ values with the $1.6 \mathrm{~mm}$ tube $(r=0.957)$.

It was also observed that the relationship between flow rate $Q$ and the $\Delta P$ is not linear. However, it is important to note that given the specifications of the pump manufacturer, the flow will always be the same function of supply voltage and pumping tubes.

The Re Reynolds number estimates and the $L_{\text {min }}$ minimum distance to obtain laminar flow were determined from the data $Q$ flow, depending on the voltage supply to the pump. The observed maximum predicted for the phantom $R e$ is equal to 1134.07 , which does not exceed 2000; therefore, the flow tends to be laminar (Fox and McDonald, 2010). The possibility of laminar flow in the measurement segment is also confirmed by obtaining $13 \mathrm{~cm}$ higher $L_{\min }$ in the case of higher flow; as a result, a $14 \mathrm{~cm}$ length was adopted in the experimental setup.

The comparison between the resistance $R$ of the experimental and theoretical hydraulic systems (Figure 2) shows the similarity between the two results, especially in cases of higher flow $(4.8$ and $3.2 \mathrm{~mm}$ pumping tubes) where the $r$ Pearson correlation coefficients between the curves are 0.998 and 0.997 , respectively. However, for lower flow tubes $(1.6 \mathrm{~mm})$, the curves have different values, with $r=0.957$ (Figure 3). The graph analysis of the dispersion linear regression of the three resistances (Figure 3) also verifies a smaller slope coefficient in the case of a higher flow rate (1.098 for the $4.8 \mathrm{~mm}$ tube and 1.527 for the $3.2 \mathrm{~mm}$ tube) and a greater one at lower flows ( 1.950 with the $1.6 \mathrm{~mm}$ tube), with a lower correlation. This can be attributed to the lower accuracy of the experimental measurements in the case of lower pressure differential gradients.

It is noted that if this system is to be used with blood-mimicking fluid to calibrate flowmeters according to the Doppler method, the pressure-flow relationships presented here should be measured again because the rheological properties are different. As an example, in Ramnarine et al. (1998), which studied a fluid with a sound propagation velocity similar to that of blood $\left(1548 \pm 5 \mathrm{~m} \cdot \mathrm{s}^{-1}\right)$, the viscosity $(4.10 \pm 0.10 \mathrm{mPa} . \mathrm{s})$ was greater than that of water (1.00 mPa.s); thus, new tests with the flow phantom proposed here are needed before it can be used.
Initial results and the fluid mechanic parameters have been presented in congresses (Silva et al., $2008 ; 2010$ ). The flow phantom model presented in this paper was used as the evaluation method for ultrasonic transducers for TTFM, and satisfactory results were reported in Jiménez et al. (2010) and Ortega-Palacios et al. (2012).

The next step would be the simulation of pulsatile flow and the calibration required to study the sensitivity of TTFM. Other steps would include characterizing the acoustic and elastic properties of silicone tubes and using a fluid similar to blood with regard to rheological properties to enable the calibration of Doppler ultrasonic flowmeters.

A phantom was designed and built to be capable of generating flow values similar to the ones observed in coronary bypass for the calibration of flow measurement in coronary surgery by TTFM systems. The resistance curves are a function of pressure and flow, were obtained in experimental tests using water, and are in agreement with the theoretical model based on fluid mechanic equations. This phantom generates known constant flows and is simple to assemble and cheap to make (about $\$ 250.00$ U.S. dollars); therefore, it is ready to be implemented in TTFM calibrations.

\section{References}

Amaral SL, Michelini LC. Validation of transit-time flowmetry for chronic measurements of regional blood flow in resting and exercising rats. Brazilian Journal of Medical and Biological Research, 1997; 30:897-908. PMid:9361716. http://dx.doi.org/10.1590/S0100-879X1997000700013

Bednarik JA, May CN. Evaluation of a transit-time system for the chronic measurement of blood flow in conscious sheep. Journal of Applied Physiology. 1995; 78(2):524-30. PMid:7759421.

Beldi G, Bosshard A, Hess OM, Althaus U, Walpoth BH. Transit-time flow measurement: experimental validation and comparison of three different systems. Annals of Thoracic Surgeons. 2000; 70:212-7. http://dx.doi.org/10.1016/S00034975(00)01246-7

Berry C, L'Allier PL, Grégoire J, Lespérance J, Levesque S, Ibrahim R, Tardif JC. Comparison of intravascular ultrasound and quantitative coronary angiography for the assessment of coronary artery disease progression. Circulation. 2007; 115(14):1851-7. PMid:17389269. http://dx.doi.org/10.1161/ CIRCULATIONAHA.106.655654

Canver CC, Cooler SD, Murray EL, Nichols RD, Heisey DM. Clinical importance of measuring coronary graft flows in the revascularized heart. Ultrasonic or electromagnetic? Journal of Cardiovascular Surgery. 1997; 38:211-5.

Dean DA, Jia CX, Cabreriza SE, D'Alessandro DA, Dickstein ML, Sardo MJ, Chalik N, Spotnitz HM. Validation study of a new transit-time ultrasonic flow probe for continuous great vessel measurements. ASAIO Journal. 1996; 42:M671- 
6. PMid:8944965. http://dx.doi.org/10.1097/00002480199609000-00072

Drost CJ. Vessel diameter-independent volume flow measurements using ultrasound. Proceedings of the San Diego Biomedical Symposium. 1978; 17:299-302.

Fox RW, McDonald AT. Introdução à mecânica dos fluidos. 7. ed. Rio de Janeiro: LTC; 2010.

Gordon I. Effects of stenosis on transit-time ultrasound measurement of blood flow. Ultrasound in Medicine \& Biology. 1995; 21(5):623-33. http://dx.doi.org/10.1016/03015629(95)00005-C

Groom R, Tryzelaar J, Forest R, Niimi K, Cecere G, Donegan D, Katz S, Weldner P, Quinn R, Braxton J, Blank S, Kramer R, Morton J. Intra-operative quality assessment of coronary artery bypass grafts. Perfusion. 2001; 16:511-8. PMid:11761091. http://dx.doi.org/10.1177/026765910101600611

Hein IA, O'Brien WD. A flexible blood flow phantom capable of independently producing constant and pulsatile flow with a predictable spatial flow profile for ultrasound flow measurement validations. IEEE Transactions on Biomedical Engineering. 1992; 39(11):1111-22. PMid:1487274. http:// dx.doi.org/10.1109/10.168687

Hirotani T, Kameda T, Shirota S, Nakao Y. An evaluation of intraoperative transit-time measurement of coronary bypass flow. European Journal of Cardio-thoracic Surgery. 2001; 19:848-52. http://dx.doi.org/10.1016/S1010-7940(01)00700-X

Jiménez A, Carrillo E, Moreno E, Torres D, Ramos A, Calas H, Sanz PT, Krüger MA, Pereira WCA. Sistema para medir flujo sanguíneo em vasos empleando la técnica "tiempo de tránsito" ultrasónico. In: Pan American Health Care Exchanges (PAHCE); 2010 Mar 15-19; Lima. Lima; 2010. p. 149-54.

Laustsen J, Pedersen EM, Terp K, Steinbrüchel D, Kure HH, Paulsen PK, Jorgensen H, Paaske WP. Validation of a new transit-time flowmeter in man. European Journal of Endovascular Surgery. 1996; 12:91-6. http://dx.doi. org/10.1016/S1078-5884(96)80282-6

Lundell A, Bergqvist D, Mattsson E, Nilsson B. Volume blood flow measurements with a transit-time flowmeter: an in vivo and in vitro variability and validation study. Clinical physiology. 1993; 13:547-57. PMid:8222539. http://dx.doi. org/10.1111/j.1475-097X.1993.tb00470.x

Mello-Aires M. Fisiologia. 3. ed. Rio de Janeiro: Guanabara Koogan; 2008.

Ortega-Palacios R, Pereira WCA, von Krüger MA, Vera A, Leija L. Ultrasound transit-time blood flowmeter calibration. In: Congresso Brasileiro de Engenharia Biomédica: Anais do XXIII Congresso Brasileiro de Engenharia Biomédica; 2012 Out 1-5; Porto de Galinhas. Rio de Janeiro: SBEB; 2012. p. 2413-7.

Poepping TL, Nikolov HN, Thorne ML, Holdsworth DW. A thin-walled carotid vessel phantom for Doppler ultrasound flow studies. Ultrasound in Medicine \& Biology. 2004; 30(8):1067-78. PMid:15474751. http://dx.doi.org/10.1016/j. ultrasmedbio.2004.06.003

Ramnarine KV, Nassiri DK, Hoskins PR, Lubbers J. Validation of a new blood-mimicking fluid for use in Doppler flow test objects. Ultrasound in Medicine \& Biology. 1998; 24(3):451-9. http://dx.doi.org/10.1016/ S0301-5629(97)00277-9

Rickey DW, Picot A, Christopher DA, Fenster A. A wall-less vessel phantom for Doppler ultrasound studies. Ultrasound in Medicine \& Biology. 1995; 21(9):1163-76. http://dx.doi. org/10.1016/0301-5629(95)00044-5

Sanderson ML, Yeung H. Guidelines for the use of ultrasonic non-invasive metering techniques. Flow Measurement and Instrumentation. 2002; 13:125-42. http://dx.doi.org/10.1016/ S0955-5986(02)00043-2

Silva FAM, Von Krüger MA, Martins VC, Pereira WCA. Phantom de fluxo para calibração de fluxômetro por tempo de transito ultra-sônico. In: Congresso Brasileiro de Engenharia Biomédica: Anais do XXI Congresso Brasileiro de Engenharia Biomédica; 2008 Nov 16-20; Salvador. Rio de Janeiro: SBEB; 2008. p. 1139-42.

Silva FAM, Von Krüger MA, Pereira WCA. Modelo de phantom de fluxo constante para calibração de fluxômetros biomédicos. In: Congresso Brasileiro de Engenharia Biomédica: Anais do XXII Congresso Brasileiro de Engenharia Biomédica; 2010 Nov 21-25; Tiradentes. Rio de Janeiro: SBEB; 2010. p. 1110-3.

Transonic System Inc. Flow probe bench calibration. Transonic [Internet]. [acesso em 2009 jun 07]. Disponível em: http://www.transonic.com/calibration.shtml.

Tabrizchi R, Pugsley MK. Methods of blood flow measurement in the arterial circulatory system. Journal of Pharmacological and Toxicological Methods. 2000; 44:37584. http://dx.doi.org/10.1016/S1056-8719(00)00123-4

Walpoth BH, Bosshard A, Genyk I, Kipfer B, Berdat PA, Hess OM, Althaus U, Carrel PC. Transit-time flow measurement for detection of early graft failure during myocardial revascularization. Annals of Thoracic Surgery. 1998; 66:1097-100. http://dx.doi.org/10.1016/S00034975(98)00653-5

\section{Authors \\ Fellipe Allevato Martins da Silva*, Marco Antônio von Krüger, Wagner Coelho de Albuquerque Pereira Centro de Tecnologia, Programa de Engenharia Biomédica, Instituto Alberto Luiz Coimbra de Pós-Graduação e Pesquisa de Engenharia - COPPE, Universidade Federal do Rio de Janeiro - UFRJ, Av. Horácio Macedo 2030, B1. H, Sala 327, Cidade Universitária, Rio de Janeiro, RJ, Brasil.}

